\title{
The environmental fate of phosphorus locked away in iron minerals
}

\author{
PETER KRAAL ${ }^{1}$, CASE VAN GENUCHTEN ${ }^{2}$ AND THILO \\ BEHRENDS $^{3}$ \\ ${ }^{1}$ Royal Netherlands Institute for Sea Research \\ ${ }^{2}$ Department of Geochemistry, Geological Survey of Denmark \\ and Greenland \\ ${ }^{3}$ Utrecht University \\ Presenting Author: peter.kraal@nioz.nl
}

Iron oxides $(\mathrm{FeOx})$ are minerals with a high capacity to bind and sequester phosphorus (P). In this way, $\mathrm{FeOx}$ help control the mobility and bioavailability of this key nutrient that is, in many terrestrial and coastal aquatic systems, a contaminant. Because $\mathrm{P}$ sorption in turn affects the structure and reactivity of $\mathrm{FeOx}$, a complex and poorly understood interplay exists between the environmental fates of $\mathrm{FeOx}$ and $\mathrm{P}$. Elucidating this interplay is important to constrain the role of $\mathrm{FeOx}$ in $\mathrm{P}$ burial under different depositional (redox) conditions. Here, we explore the structure of P-bearing $\mathrm{FeOx}$ and their environmental fate in a series of laboratory and field experiments. Synthetic amorphous and crystalline $\mathrm{FeOx}$ with sorbed $\mathrm{P}$ were exposed to the common dissolved reductants ferrous iron $\left(\mathrm{Fe}^{2+}\right)$ and sulfide $\left(\mathrm{H}_{2} \mathrm{~S}\right)$ in freshwater and salt marsh sediments as well as under controlled laboratory conditions. For the former, we used a novel diffusive sampler approach that allowed us to investigate in detail the transformation of target phases under fully natural conditions [1]. $\mathrm{FeOx}$ transformations and $\mathrm{P}$ release were tracked over several weeks with chemical and (micro)spectroscopic methods. Our results show that $\mathrm{Fe}^{2+}$-catalyzed crystallization of P-bearing amorphous $\mathrm{FeOx}$ was strongly inhibited and $\mathrm{P}$ remained sequestered in the FeOx. This suggests a feedback whereby high $\mathrm{P}$ concentrations (for instance in eutrophic systems) result in the formation of poorly ordered, P-rich $\mathrm{FeOx}$ that have an extended lifetime, thus boosting the (short-term) sedimentary $\mathrm{P}$ retention capacity. Conversely, exposure to $\mathrm{H}_{2} \mathrm{~S}$ resulted in extensive $\mathrm{FeOx}$ transformation (sulfidation) - even accelerated for $\mathrm{P}$ bearing $\mathrm{FeOx}$ - and P release. Lastly, an inoculated incubation experiment using a mixture of natural sediment and synthetic $\mathrm{FeOx}$ showed that microbial $\mathrm{FeOx}$ reduction rates were higher for P-bearing $\mathrm{FeOx}$ compared to pure $\mathrm{FeOx}$. Overall, we show diverging effects of $\mathrm{P}$ sorption on $\mathrm{FeOx}$ reactivity towards different reducing agents and our results underpin the profound impact of the anoxic-to-sulfidic transition on coupled Fe-P cycling.

[1] Kraal et al. (2020), Environ. Sci. Techn. 54, 12795-12802 